International Journal of

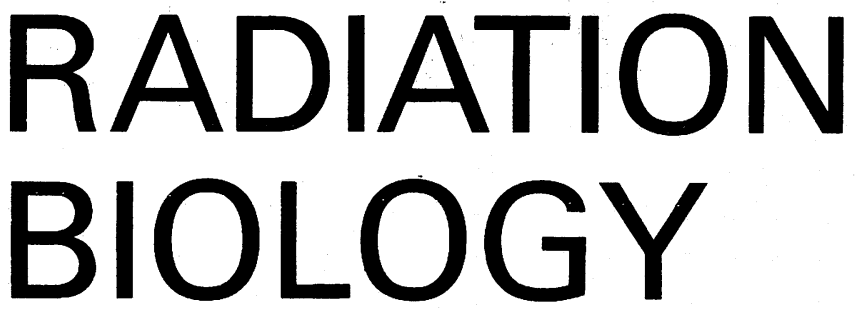

CONTENTS

\title{
MUTATIONS
}

Mutation induction by ionizing radiation in three human bladder tumour cell lines

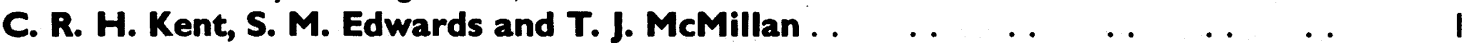

\section{DNA DAMAGE}

Application of programmable, autonomously controlled electrode (PACE) technology to the development of an improved pulsed field gel electrophoresis assay for DNA double-strand breaks in mammalian cells (Technical report)

M. C. Elia and $\boldsymbol{W}$. $\boldsymbol{W}$. Nichols $\ldots \begin{array}{llllllllll} & \ldots\end{array}$

A correlation between DNA-nuclear matrix binding and relative radiosensitivity in two human squamous cell carcinoma cell lines

A. E. Milner, D. J. Gordon, B. M. Turner and A. T. M. Vaughan $\quad \ldots \quad \ldots \quad \ldots$

\section{MEMBRANES}

The fusion radiosensitivity of differentiating chick embryo myoblasts in vitro is not determined by the plasma membrane

M. T. Santini, C. Cametti, E. Straface and P. L. Indovina $\quad \ldots \quad$. . $\quad \ldots \quad \ldots \quad \ldots \quad 21$

\section{SENSITIZERS/PROTECTORS}

Relationship between intracellular concentration and radiosensitizing effect of pimonidazole and etanidazole on two human melanoma cell lines

R. El Gamoussi, I. J. Stratford, and M. Guichard . . . . . . . . . . .

Effects of WR-1065 and WR-151326 on survival and neoplastic transformation in C3H/10T $\frac{1}{2}$ cells exposed to TRIGA and JANUS fission neutrons

E. K. Balcer-Kubiczek, G. H. Harrison, C. K. Hill and W. F. Blakely. . . . . $\quad \ldots \quad 37$

MODELLING

Cell recovery kinetics for split-dose, multifractionated and continuous irradiation in the DSB model

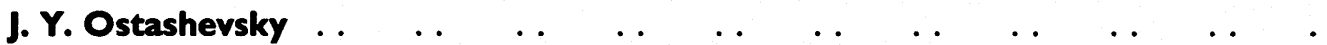




\section{BONE MARROW}

Residual haematopoietic damage in adult and 8 day-old mice exposed to $7 \mathrm{~Gy}$ of $\mathrm{X}$-rays

T. Grande, S. Gaitán, C. Tejero, and J. A. Bueren . . $\quad \ldots \quad \ldots \quad \ldots \quad \ldots \quad \ldots$

HYPERTHERMIA

Induction of quiescent S-phase cells by irradiation and/or hyperthermia. I. Time and dose dependence

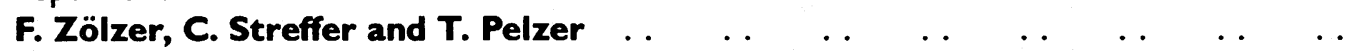

Induction of quiescent S-phase cells by irradiation and/or hyperthermia. II. Correlation with colony forming ability

F. Zölzer, C. Streffer and T. Pelzer $\ldots \begin{array}{llllllllllll} & \ldots & \ldots & \ldots & \ldots & \ldots & \ldots & \ldots & \ldots & & 77\end{array}$

Latent $\mathrm{X}$-ray damage in the rat sciatic nerve results in delay in functional recovery after a heat treatment

H. H. de Vrind, W. M. van Dam, J. Wondergem and J. Haveman . . . . . .

\section{BIOLOGICAL DOSIMETRY}

Hair cortical cell counts (HCCC), a new sensitive in vivo assay with possible applications for biological dosimetry (Technical report)

C. S. Potten

(Technical report)

Hair medullary cell counts following low-dose-rate $\gamma$ - and high-energy neutron irradiation

C. S. Potten . .

FOOD IRRADIATION

Detection of irradiated food-methods and routine applications

G. A. Schreiber, N. Helle and K. W. Bögl $\ldots \begin{array}{llllllllll} & \ldots & \ldots & \ldots & \ldots & \ldots & \ldots & \ldots & 105\end{array}$

MEETING REPORT

6 émes journées d'Etudes sur la Chimie sous Rayonnement (JECR-92)

A. J. Swallow

OBITUARY

Hendrik Athos Sidney van den Brenk, 1921-1992

H. B. Hewitt

$\begin{array}{lllllllllllllll}\text { Diary of events } & \ldots & \ldots & \ldots & \ldots & \ldots & \ldots & \ldots & \ldots & \ldots & \ldots & \ldots & 135\end{array}$

$\begin{array}{llllllllllllll}\text { Forthcoming Papers } & \ldots & \ldots & \ldots & \ldots & \ldots & \ldots & \ldots & \ldots & \ldots & \ldots & 137\end{array}$ 
INT. J. RADIAT. BIOL., 1993, vol. 63, No. 2, 173-181

\title{
Application of pulsed field gel electrophoresis to determine $\gamma$-ray- induced double-strand breaks in yeast chromosomal molecules
}

\author{
A. A. FRIEDL $\dagger$, W. BEISKER $\ddagger$, K. HAHN $\dagger$, F. EGKARDT-SCHUPP* $\dagger$ \\ and A. M. KELLERER $\dagger$
}

(Received 27 May 1992; revision received 13 August 1992; accepted 24 August 1992)

\begin{abstract}
The frequency of DNA double-strand breaks (dsb) was determined in yeast cells exposed to $\gamma$-rays under anoxic conditions. Genomic DNA of treated cells was separated by pulsed field gel electrophoresis, and two different approaches for the evaluation of the gels were employed: (1) The DNA mass distribution profile obtained by electrophoresis was compared to computed profiles, and the number of DSB per unit length was then derived in terms of a fitting procedure; (2) hybridization of selected chromosomes was performed, and a comparison of the hybridization signals in treated and untreated samples was then used to derive the frequency of dsb. The two assays gave similar results for the frequency of dsb $\left((1.07 \pm 0.06) \times 10^{-9} \mathrm{~Gy}^{-1} \mathrm{bp}^{-1}\right.$ and $(0.93 \pm 0.09) \times 10^{-9}$ $\mathrm{Gy}^{-1} \mathrm{bp}^{-1}$, respectively). The dsb frequency was found to be linearly dependent on dose.
\end{abstract}

\section{Introduction}

Ionizing radiation induces a variety of damage in deoxyribonucleic acid (DNA), among which DNA double-strand breaks (dsb) are considered to be a major cause of cell killing (reviewed by Ward 1990). Studies in various eukaryotic systems have led to the conclusion that one or two unrepaired dsb per cell are lethal (Ho 1975, Resnick and Martin 1976, Frankenberg et al. 1981, Blöcher and Pohlit 1982).

During recent years several methods have been established employing pulsed field gel electrophoresis (PFGE) to detect dsb in mammalian DNA. Intact mammalian chromosomes are too large to enter pulsed field gels. The methods published so far therefore resemble sedimentation or elution assays; they determine the average DNA fragment size resulting from irradiation (Ahn et al. 1991) or the fraction of DNA able to enter the gel after irradiation (Ager and Dewey 1990, Ager et al. 1990, Blöcher et al. 1989, Blöcher 1990, Blöcher and Kuhni 1990, Iliakis et al. 199la,b, Stamato and Denko 1990).

With the yeast Saccharomyces cerevisiae an alternative approach has been used for the analysis of the

*Author for correspondence.

†GSF-Institut für Strahlenbiologie and $\ddagger$ GSF-Institut für Biophysik, Ingolstädter Landstraße 1, D-8042 Neuherberg, Germany induction and repair of dsb and of radiation-induced $\mathrm{S} 1$ nuclease-sensitive sites that were processed to dsb (Geigl et al. 1986, Geigl and Eckardt-Schupp 1990, $1991 \mathrm{a}, \mathrm{b})$. Yeast chromosomal molecules can be separated according to their size by PFGE, and they form distinct bands in ethidium bromide-stained gels. If it is assumed that $\gamma$-rays cause dsb that are uniformly distributed throughout the genome, one can compute the average number of dsb per molecule of a specified size from the fraction of chromosomal molecules in a particular band that remain unbroken after dsb induction. This fraction is, however, overestimated if one fails to correct for the fragments of larger chromosomes that co-migrate with intact smaller chromosomal molecules.

The aim of this study was to examine two different approaches for the quantification of dsb in yeast. Both approaches use PFGE. In the first approach the dsb frequency is determined by comparing the distribution of molecular lengths in the gels for irradiated and unirradiated yeast cells with computed distributions. The distributions in the gel are examined by densitometry of photonegatives taken from ethidium bromide-stained gels. The computed distributions are obtained by assuming random breaks among the known spectrum of chromosome molecules. In the second approach, Southern blots of pulsed field gels were hybridized with chromosomespecific DNA probes; the fraction of molecules of the specified chromosome that remained intact after irradiation was then determined by a comparison of the integrated hybridization signals of the corresponding band in the untreated and the treated samples.

\section{Material and methods}

\subsection{Strain of Saccharomyces cerevisiae}

In all experiments we used the diploid repairproficient strain BK0, which was kindly provided by B. A. Kunz (Kunz and Haynes 1982). 


\subsection{Media, culture and irradiation}

Yeast cells were grown at $30^{\circ} \mathrm{C}$ in YEPD medium ( $1 \%$ yeast extract, $2 \%$ bacto peptone, $2 \%$ glucose) for 2 days, until stationary growth phase was reached. Cells were harvested by centrifugation, washed twice in ice-cold $0.1 \mathrm{M} \quad \mathrm{Na}_{2} \mathrm{HPO}_{4}$ / $\mathrm{NaH}_{2} \mathrm{PO}_{4}(\mathrm{pH} 7 \cdot 0)$ and resuspended at a concentration of $5 \times 10^{8}$ to $2 \times 10^{9}$ cells $/ \mathrm{ml}$. The cell suspension was maintained on ice and, in order to avoid indirect DNA damage by oxygen-mediated radical production, it was bubbled with nitrogen for $30 \mathrm{~min}$ prior to irradiation and during irradiation. Irradiation was performed on ice in a ${ }^{60} \mathrm{Co}-\gamma$-cell (Atomic Energy of Canada, Ltd) at a dose-rate of $38 \mathrm{~Gy} / \mathrm{min}$.

Immediately after irradiation samples of $1 \mathrm{ml}$ were taken, and EDTA was added to a final concentration of $75 \mathrm{~mm}$ to inhibit enzymatic repair of DNA damage.

\subsection{DNA preparation}

The DNA preparation was carried out with minor modifications as described earlier (Geigl and Eckardt-Schupp 1990). Briefly, cells were harvested by centrifugation and were resuspended in $600 \mu \mathrm{l}$ $50 \mathrm{~mm}$ EDTA (pH 7.5); $200 \mu$ l SEC-buffer (10 mm citrate-phosphate buffer $(\mathrm{pH} 7 \cdot 0), 1 \mathrm{~m}$ sorbitol, $100 \mathrm{~mm}$ EDTA), $10 \mu \mathrm{l} \beta$-mercaptoethanol, and $0.8 \mathrm{mg}$ Zymolase 100T (Seikagaku Kogyo Co. Ltd, Tokyo) were added. The suspension was mixed rapidly with $800 \mu \mathrm{l}$ of $2 \%$ low-melting-point agarose (Sigma) in $0.125 \mathrm{~m}$ EDTA at $44^{\circ} \mathrm{C}$. Plugs of $150 \mu \mathrm{l}$ volume were then made in a suitably formed mould. After gelation $\left(30 \mathrm{~min}, 4^{\circ} \mathrm{C}\right)$ the plugs were transferred to a Falcon tube which contained $1.8 \mathrm{ml} 0.5 \mathrm{M}$ EDTA (pH 9.0), $20 \mu \mathrm{l} \mathrm{l} \mathrm{m}$ Tris $\mathrm{HCl}(\mathrm{pH} 7.5)$ and $30 \mu \mathrm{l} \mathrm{H}_{2} \mathrm{O}$. The cell walls were lysed during incubation at $37^{\circ} \mathrm{C}$ for $1 \mathrm{~h}$. Subsequently the lysis buffer was substituted by proteinase-K solution $(1.8 \mathrm{ml} 0.5 \mathrm{M}$ EDTA (pH 9.0), $20 \mathrm{mg} N$-lauroylsarcosine, $2 \mathrm{mg}$ proteinase-K (Sigma), and $20 \mu \mathrm{l} 1 \mathrm{~m}$ Tris $\mathrm{HCl}$ $(\mathrm{pH} 7 \cdot 5))$. The plugs were incubated overnight at $50^{\circ} \mathrm{C}$ in this solution; subsequently they were rinsed in $10 \mathrm{~mm}$ Tris $\mathrm{HCl}$ ( $\mathrm{pH} 7.5), 10 \mathrm{~mm}$ EDTA and stored in the rinsing buffer at $4^{\circ} \mathrm{C}$.

\subsection{Pulsed field gel electrophoresis}

Two different electrophoresis systems were used: The 'transverse alternating field electrophoresis' system (TAFE), (Beckman Instruments), and the 'contour clamped homogeneous electric field' system
(CHEF) (Bio-Rad). For both systems electrophoresis parameters were established which lead to a relation between migration distance and molecule size that deviates only moderately from linearity between 200 and $1100 \mathrm{kbp}$. The length of chromosomal molecules in the strain $\mathrm{BK} 0$ was determined by comparison with concatemers of phage $\lambda$ and the standard strain YNN295 (Bio-Rad).

The preparation of the running buffer and the casting of $1 \%$ agarose gels followed the recommendations of the manufacturers. Agarose plugs were loaded into the slots directly or after melting for 3 $\min$ at $65^{\circ} \mathrm{C}$. Subsequently the slots were sealed with liquid agarose.

TAFE gels were run at a constant current of $160 \mathrm{~mA}$ for $18 \mathrm{~h}$ with $60 \mathrm{~s}$ pulse time. The buffer temperature was kept at $15^{\circ} \mathrm{C}$. CHEF gels were run at $180 \mathrm{~V}$ constant voltage with a program of two phases. The first phase consisted of $14 \mathrm{~h}$ run time with $60 \mathrm{~s}$ pulse time, the second phase of $14 \mathrm{~h}$ run time with $90 \mathrm{~s}$ pulse time. The buffer temperature was kept at $14^{\circ} \mathrm{C}$.

After electrophoresis the gels were stained for $2 \mathrm{~h}$ in $200 \mathrm{ml}$ running buffer which contained $100 \mu \mathrm{g}$ ethidium bromide; subsequently they were destained for several hours. Photographs were taken with a Polaroid-type 665 positive/negative film on a transilluminator (Bachofer, Germany, $302 \mathrm{~nm}$ ). Photonegatives were developed and cleared as suggested by the manufacturer, and were scanned with a laser densitometer (UltroScan XL, Pharmacia LKB Biotechnology). The scans were taken with the GelScan XL program (Pharmacia LKB). Each lane of a gel was scanned three times.

\subsection{Southern hybridization}

Blotting of the gels was performed according to Smith et al. (1988). After photography the gels were exposed to UV light on the transilluminator for 8 min, to nick the high molecular DNA. The DNA was denaturated by treating the gel for $30 \mathrm{~min}$ in $0.5 \mathrm{M}$ $\mathrm{NaOH}, 0.5 \mathrm{M} \mathrm{NaCl}$. After neutralization in $1.5 \mathrm{M}$ $\mathrm{NaCl}, 0.5 \mathrm{~m}$ Tris $\mathrm{HCl}(\mathrm{pH} 7.5)$ the DNA was transferred to a nylon membrane (Biodyne, Pall) with $20 \times$ SSC transfer buffer. After blotting for $48 \mathrm{~h}$ the membrane was washed briefly in $2 \times$ SSC buffer and was then air-dried. The DNA was crosslinked to the membrane by UV-irradiation for $2.5 \mathrm{~min}$.

The following plasmids were used for the isolation of appropriate chromosome-specific DNA probes: pDP14 and pDP19 containing centromeric sequences of chromosome $\mathrm{X}$ and XIV, respectively, were kindly provided by D. Jäger and P. Phillipsen. 
A probe for the gene ADH4 was isolated from $\mathrm{p} 441$; a probe for the gene PHO5 from clone4. Plasmids p44l and clone 4 were kindly donated by C. Morawetz and W. Hörz, respectively. A probe for the gene URA3 was isolated from the commercially available vector YIp5. Restriction digests of the plasmids and electrophoretic isolation of the desired fragments were performed according to standard procedures.

DNA probes were labelled with digoxigenindUTP by use of the DIG DNA labelling and detection kit (Boehringer Mannheim, Germany). Filters were prehybridized for $1 \mathrm{~h}$ at $68^{\circ} \mathrm{C}$ in $50 \mathrm{ml}$ hybridization solution $(5 \times \mathrm{SSC}, 0.1 \% \mathrm{~N}$-lauroylsarcosine, $0.02 \%$ SDS, $1 \%$ blocking reagent) according to the Boehringer protocols. Hybridization was performed overnight at $68^{\circ} \mathrm{C}$ with $3 \mathrm{ml}$ hybridization solution that contained about $0.5 \mu \mathrm{g}$ labelled DNA probe. Filters were washed $2 \times 5 \mathrm{~min}$ at room temperature with $2 \times \mathrm{SSC}, 0 \cdot 1 \% \mathrm{SDS}$, and $2 \times 15 \mathrm{~min}$ at $68^{\circ} \mathrm{C}$ with $0 \cdot 1 \times \mathrm{SSC}, 0 \cdot 1 \% \mathrm{SDS}$.

\subsection{Detection of digoxigenin-labelled hybrids}

The detection reaction was performed according to the protocol developed by G. Michaelis (unpublished). Briefly, the filters were blocked to avoid unspecific binding of the alkaline phosphatasecoupled anti-digoxigenin antibodies. After antibody binding and removal of unbound antibodies the membrane was incubated with a solution that contained the chemiluminescence substrate AMPPD (Tropix, USA). The membrane was then enveloped in Saran wrap and exposed on an X-ray film for $30 \mathrm{~min}$ at room temperature. The developed X-ray films were scanned densitometrically.

\subsection{Quantitative model for the distribution of DNA in PFGE gels}

2.7.1. Distribution of molecular lengths. It is assumed that $\gamma$-ray-induced dsb are independently and uniformly distributed, i.e. at the same frequency $(\alpha)$ per unit length of DNA, in all molecules (Frankenberg-Schwager et al. 1979, Blöcher 1982). The formula derived by Schulz (1942) for this random breakage model can then be applied. Assume a molecule, $i$, with molecular length $S_{i}$. When this molecule is subjected to random breakage one obtains the fraction of DNA mass that is contained in molecules of length less than $S$ :

$$
M_{i}(S)=1-\mathrm{e}^{-\alpha S}\left(1+\alpha S\left(1-\frac{S}{S_{i}}\right)\right), \text { with } S \leqslant S_{i}
$$

This is also called the sum distribution of DNA in molecular length, $S$. By differentiation of $M(S)$ one obtains the differential distribution, $m_{i}(S)$, of DNA in molecular length:

$$
\begin{aligned}
m_{i}(S) & =\frac{\mathrm{d} M_{i}(S)}{\mathrm{d} S} \\
& =\alpha^{2} S \mathrm{e}^{-\alpha S}\left(1+\frac{2}{\alpha S_{i}}-\frac{S}{S_{i}}\right)+\mathrm{e}^{-\alpha S_{i}} \delta\left(S_{i}-S\right)
\end{aligned}
$$

The last term includes the Dirac delta function $\delta\left(S_{i}-S\right)$ (a narrow peak at $S=S_{i}$ ); it represents the unbroken molecules of length $S_{i}$.

In DNA of irradiated yeast cells 16 chromosome species of length $S_{i}(i=1, \ldots, 16)$ contribute the fractions $f_{i}=S_{i} / S_{T}$ of DNA, where $S_{T}=\Sigma S_{i}$ is the total length of DNA in the chromosomes. The sum distribution of DNA in molecular length is then:

$$
\begin{aligned}
M(S) & =\sum_{i} f_{i} M_{i}(S) \\
& =1-\mathrm{e}^{-\alpha S} \sum_{\substack{i \\
\left(S_{i} \geqslant S\right)}} f_{i}\left(1+\alpha S\left(1-\frac{S}{S_{i}}\right)\right)
\end{aligned}
$$

and the differential distribution is:

$$
\begin{aligned}
m(S)= & \sum_{i} f_{i} m_{i}(S) \\
= & \alpha^{2} S \mathrm{e}^{-\alpha S} \sum_{\substack{i \\
\left(S_{i} \geqslant S\right)}} f_{i}\left(1+\frac{2}{\alpha S_{i}}-\frac{S}{S_{i}}\right) \\
& +\sum_{i} f_{i} \mathrm{e}^{-\alpha S_{i}} \delta\left(S_{i}-S\right)
\end{aligned}
$$

2.7.2. Distribution in migration distance. The smaller the molecular length, $S$, the larger is the migration distance, $x$. Knowing the dependence $S(x)$, i.e. the calibration curve, one can transform the distribution of DNA in molecular length into the distribution in migration distance. This transformation is trivial for the sum distribution. If $G(x)$ is the fraction of DNA at migration distances less than $x$, one has the relation:

$$
G(x)=1-M(S), \quad \text { with } S=S(x)
$$

For the differential distribution one obtains:

$$
\begin{aligned}
g(x) & =\frac{\mathrm{d} G(x)}{\mathrm{d} x}=\frac{\mathrm{d} M(S)}{\mathrm{d} S} \frac{\mathrm{d} S}{\mathrm{~d} x} \\
& =\frac{\mathrm{d} S}{\mathrm{~d} x} m(S)
\end{aligned}
$$

where $\mathrm{d} S / \mathrm{d} x$ is the slope of the calibration curve. This means that the amplitude of the observed spectrum contains, next to $m(S)$, the slope of the 
dependence $S(x)$. The two spectra $g(x)$ and $m(S)$ have different shapes, unless the calibration curve $S(x)$ is linear.

The actual distribution of DNA in migration distance is subject to variations of $x$, even at specified $S$. In an adequate approximation one can represent the variations by a Gaussian distribution

$$
h(x)=\frac{1}{\sqrt{2 \pi} \sigma} \mathrm{e}^{-\left(x-x^{\prime}\right)^{2} / 2 \sigma^{2}}
$$

where $x^{\prime}$ is the mean migration distance at specified $S$, and $\sigma$ is the standard deviation of the distribution. The full width at half peak value, a usual parameter for the peak width, is equal to $2 \cdot 36 \sigma$. The standard deviation, $\sigma$, depends on the amount of DNA present in a band. Double bands of large chromosomes appear broader than single bands of short chromosomes. A constant $\sigma$ was, however, assumed as an adequate approximation in the present analysis. With this assumption one obtains from the ideal distribution, $g(x)$, the actual distribution, $g_{\text {obs }}(x)$ :

$$
g_{\text {obs }}(x)=\frac{1}{\sqrt{2 \pi} \sigma} \int_{0}^{x_{\max }^{\prime}} \mathrm{e}^{-\left(x-x^{\prime}\right)^{2} / 2 \sigma^{2}} g\left(x^{\prime}\right) \mathrm{d} x^{\prime}
$$

The peaks of the unbroken molecules appear, of course, as the Gaussian distributions:

$$
\frac{f_{i}}{\sqrt{2 \pi} \sigma} \mathrm{e}^{-\left(x-x_{i}\right)^{2} / 2 \sigma^{2}}
$$

where $x_{i}$ are the migration distances corresponding to the molecular lengths $S_{i}$.

2.7.3. Evaluation program. We use a program, PULSE, written in BASIC, to compute DNA distributions in migration distance in terms of equation (8). Varying the assumed value, $\alpha$, of the dsb frequency, and varying also the standard deviation, $\sigma$, of the Gaussian distribution, the program determines those parameters that provide the best fit in terms of a least-squares criterion.

The program is used interactively on a PC. After the observed distribution is read in, one has the option to choose the range of migration distances employed in the fit. In a next step one marks on the screen the positions of the chromosomes recognized in the control spectrum, i.e. in the distribution of DNA from the unirradiated sample. This permits by a suitable interpolation routine the determination of the calibration curve, $S(x)$. The type of interpolation was not specific to the CHEF or the TAFE systems; in fact one can use a simple polygon fit without substantially changing the results.

Using the specified calibration curve and the chromosomal lengths the program computes, for a matrix of different values of $\alpha$ and $\sigma$, the distributions according to equation (8), and it compares each of the resulting distributions with the observed spectrum. In each comparison a sum of squared deviations is obtained. The best estimate of the frequency of dsb is the one that corresponds to the least squared value.

The sum of the squared differences is actually calculated in two different ways in the computer program. It is either obtained by deriving the mean squared differences for the differential distributions, or the mean squared differences for the sum distributions. There is no obvious reason to prefer one of the parameters to the other, but in the present evaluations no choice was required, since the two sum-ofsquares parameters assumed their minima at the same parameter values.

The computer program PULSE can be made available on request. It contains detailed comments which need not be given in the present context.

\section{Results}

\subsection{Determination of the dsb frequency from the distribution of DNA in gels}

As stated, two different PFGE configurations were used to assay the induction of $\mathrm{dsb}$ by ${ }^{60} \mathrm{Co}-\gamma$ irradiation under anoxic conditions. Samples from five independent irradiation experiments, each performed with several doses, were analysed using the TAFE system. Samples from two independent irradiation experiments, each performed at $500 \mathrm{~Gy}$ and $1000 \mathrm{~Gy}$, were analysed in terms of the CHEF system. Examples of the gels obtained are shown in Figure 1. The loss of intact molecules caused by dsb induction is reflected by the decreasing intensity of distinct bands in irradiated samples, while the fragments of broken chromosomes contribute increasingly to the broad distribution of the 'smear'. The molecular length of the 16 chromosomes of the yeast strain BK0 was determined in separate experiments by comparison of their migration to a standard yeast strain and to concatemers of phage lambda.

Photonegatives taken from the ethidium bromidestained gels were scanned by a laser densitometer. The scanning data were obtained through the GelScan XL program (Pharmacia LKB); they were then converted to serve as input into the PULSE evaluation program. The peaks of the densitograms were identified with the corresponding chromosomes, and the lengths of these chromosomes were then used in the evaluation program to convert the 

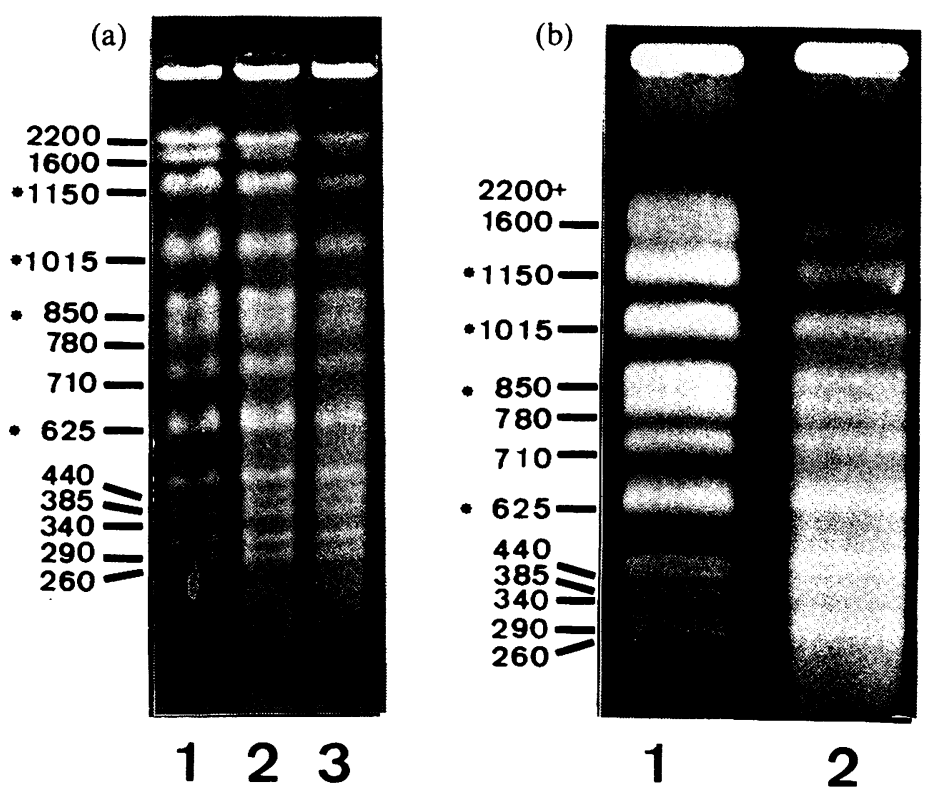

Figure 1. (a) DNA of yeast cells irradiated with $0 \mathrm{~Gy}(1), 500 \mathrm{~Gy}(2)$ and $1000 \mathrm{~Gy}(3)$ under anoxic conditions was separated using the CHEF electrophoresis system. (b) DNA of yeast cells irradiated with $0 \mathrm{~Gy}$ (1) and $1000 \mathrm{~Gy}$ (2) was separated using the TAFE system. The lengths of the individual chromosomes of the strain BK0 were determined by calibration with $\lambda$ concatemeres and yeast strain YNN295. Note that some of the bands are doublets (indicated by an asterisk). The $340 \mathrm{kbp}$ and the $385 \mathrm{kbp}$ bands represent homologous chromosomes of the diploid cell with different lengths.

distribution in molecular lengths into the distribution of migration distances. As explained in $\S 2.7$ the observed distribution was subsequently compared to the distributions computed for different assumed induction frequencies, $\alpha$, of dsb and for different widths of the peaks. To include the band width as a variable parameter in the fitting procedure was necessary, because it can be influenced even by minor variations in the electrophoresis parameters.

The best fit between the calculated and observed DNA distributions was determined in terms of a least-squares approximation either to the differential distribution or to the sum distribution (see $\S 2.7$ ). The relative merit of the two criteria may be difficult to judge, but no choice was required in the present analysis, since the two criteria led to the same fits with deviations that were small compared to the fluctuations between experiments. The examples in Figure 2 show observed distributions (dotted lines) and their calculated best fits (upper full lines) for unirradiated samples (top panel), and for samples irradiated with specified doses (lower panels). The computed distributions of fragments of broken chromosomes are separately indicated by the lower solid lines. The vertical bars indicate the ranges chosen for the fitting procedure. The two largest yeast chromosomes (estimated sizes 1600 and $2200 \mathrm{kbp}$ ) behave irregularly under the electrophoresis conditions used in the present experiments. As seen by hybridization experiments a considerable fraction of these mole- cules is trapped within the region between the wells and the band. The peaks that represent these two chromosomes were therefore excluded from the fitting procedures.

The frequencies of dsb per bp determined for
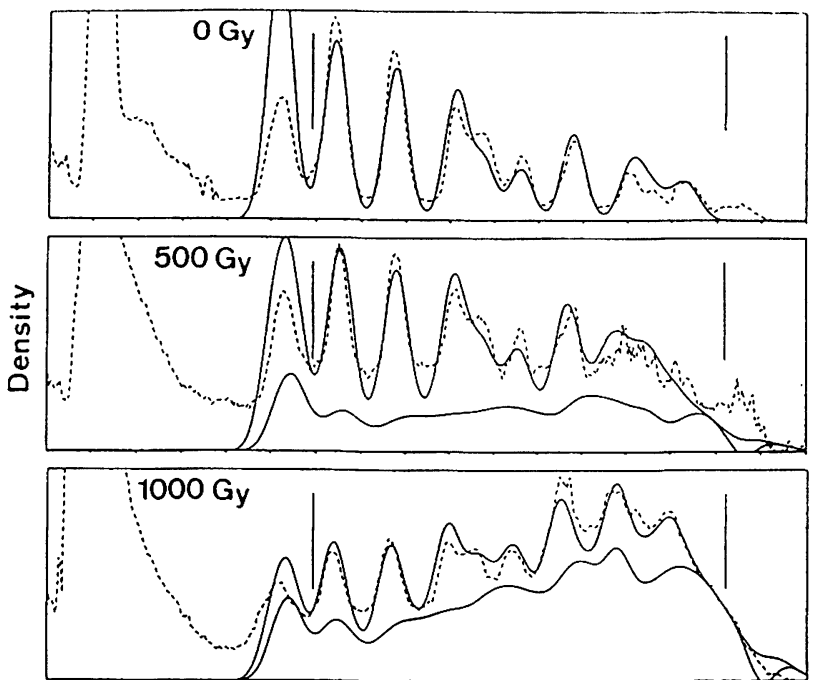

Migration Distance

Figure 2. Actual densitograms (dotted line) of gel lanes with DNA from cells exposed to $0 \mathrm{~Gy}, 500 \mathrm{~Gy}$ and $1000 \mathrm{~Gy}$, respectively. The upper solid curve represents the computed best fit. The range of migration distance over which the fit has been performed is indicated by the vertical bars. The lower solid curve represents the fragments of broken chromosomal molecules alone. 


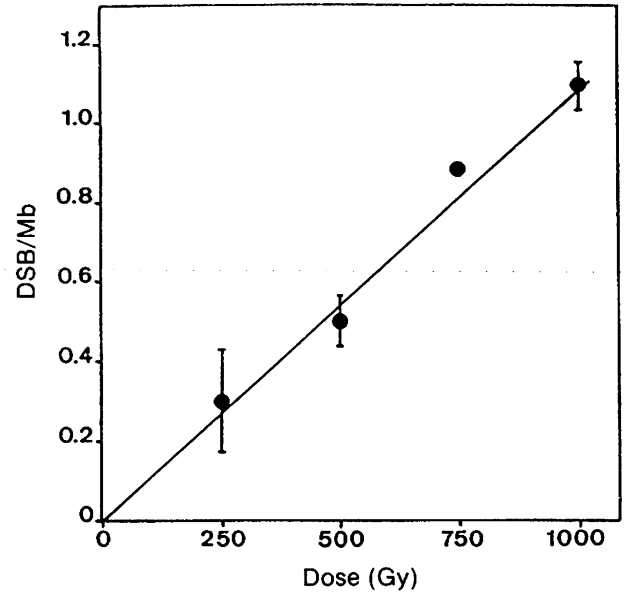

Figure 3. The number of induced dsb per bp as determined by analysis of the DNA mass distributions as a function of dose. Indicated are the mean values and standard errors from 2 (250 Gy), 9 (500 Gy), 1 (750 Gy) and 12 (1000 Gy) samples, respectively.

irradiated samples were related to the values obtained for the corresponding untreated samples. Induction of dsb in untreated samples (due to DNA degradation or shearing during the preparation) was generally very low $(<0 \cdot 15 \mathrm{dsb} / \mathrm{Mb})$.

The frequencies of dsb per bp which are obtained with this analysis are plotted as a function of dose in Figure 3. The data are consistent with a linear dependence on dose; no indication of a quadratic term is seen. The estimated frequency of dsb is $(1.07 \pm 0.06) \times 10^{-9} \mathrm{~Gy}^{-1} \mathrm{bp}^{-1}$. The means and standard errors of several experiments are indicated.

\subsection{Determination of $d s b$ frequencies by Southern hybridization}

A subset of six of the pulsed field gels was blotted and hybridized to specific probes for the chromosomes II (length $850 \mathrm{~kb}), \mathrm{V}(625 \mathrm{~kb})$, VII (1150 kb), $\mathrm{X}(780 \mathrm{~kb})$ and XIV $(850 \mathrm{~kb})$. An example is shown in Figure 4. The hybridization signal in the chromosomal band diminishes with dose, while the signal produced by fragments in the lower molecular weight region of the gel increases. The hybridization probes were labelled with the hapten digoxigenin. Binding of anti-digoxigenin antibodies which are coupled to alkaline phosphatase, and subsequent addition of the chemiluminescent substrate AMPPD, permits detection of the hybrids. Upon enzymatic dephosphorylation the AMPPD becomes unstable and decomposes with light emission (Bronstein et al. 1990). By exposure to X-ray films the light emission is registered. In measurements on calibra-

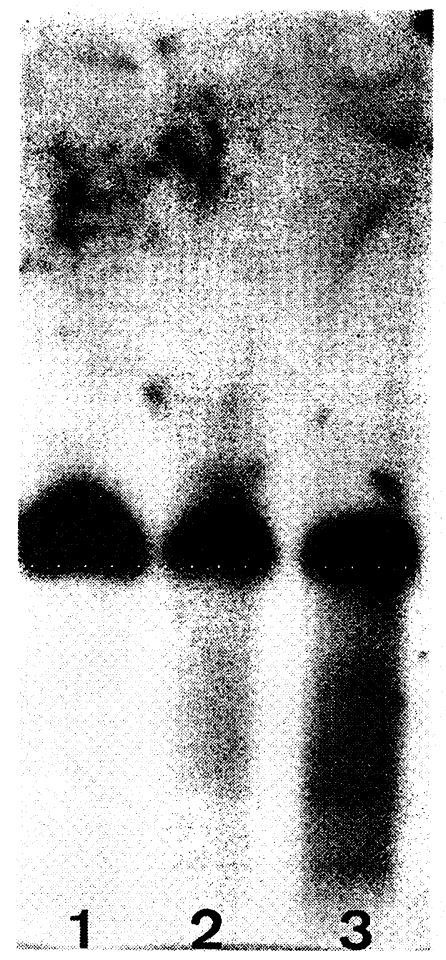

Figure 4. Southern blot of a gel where DNA from cells irradiated with $0 \mathrm{~Gy}, 500 \mathrm{~Gy}$ and $1000 \mathrm{~Gy}$, respectively, was separated. The blot was hybridized with a specific probe for chromosome $X$. The signal intensity of the chromosomal band diminishes with dose, while the heterogeneous smear of lower molecular weight increases due to fragments of broken chromosomes.

tion gels the signal, i.e. the blackening of the X-ray film, was found to be proportional to the amount of DNA in the chromosome band (see Figure 5).

The use of chromosome-specific hybridizations has the advantage that the chromosome band is well

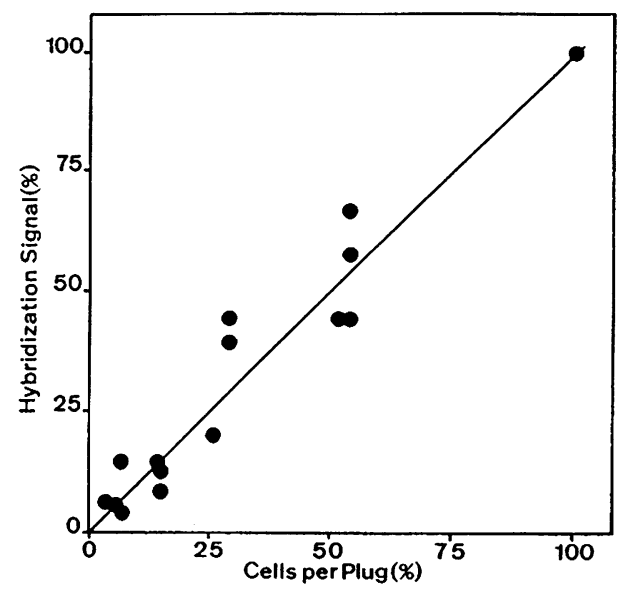

Figure 5. Plot of the signal intensities due to non-radioactive hybridization versus number of cells per agarose plug loaded. 
separated from the distribution of the fragments that carry the hybridization signal. To calculate the mean number of dsb in the chromosomal molecules of the target bands the hybridization signal in the lanes was quantified by laser densitometry of the Xray films. The signals in the chromosomal bands of irradiated samples were then compared to the corresponding signals of unirradiated samples, and the fraction of unbroken molecules after irradiation was thus obtained. The average number of dsb was then calculated on the basis of the Poisson distribution (Geigl and Eckardt-Schupp 1990). Employing this assay a dsb frequency of $(0.93 \pm 0.09) \times 10^{-9} \mathrm{~Gy}^{-1}$ $\mathrm{bp}^{-1}$ was determined. This value agrees well with the one obtained by the first approach.

\section{Discussion}

In recent years PFGE has proved to be a powerful tool for dsb analysis in mammalian DNA. The application of PFGE for dsb analysis was first described for yeast (Geigl et al. 1986, Contopoulou el al. 1987). Few publications on the subject have since appeared. The yeast system permits the detection of dsb in specific chromosomes. It can thus be used to examine a question of considerable interest: Are there regions in the genome, where dsb repair takes place preferentially? For other types of DNA damage evidence has been obtained that the position of the lesion in the DNA influences the efficiency of its repair (Hanawalt 1986, Madhani et al. 1986, Oleinick et al. 1983, Terleth et al. 1989).

In earlier work (Geigl et al. 1986, Geigl and Eckardt-Schupp 1990, 199la,b) dsb frequencies were derived from the relative intensity of distinct chromosomal bands in photonegatives taken from ethidium bromide-stained gels of irradiated and unirradiated cells. The signal of an individual band in the irradiated sample was compared to the signal of the corresponding band in the unirradiated sample. From this ratio $q$ of 'surviving', i.e. unbroken, chromosomes the average number, $n$, of dsb per chromosomal DNA molecule was calculated acording to the relation $n=-\ln q$ (Jacobs et al. 1972, Kessler et al. 1971). The approach is, however, subject to errors caused by the co-migrating fragments of larger chromosomes which overlap the bands corresponding to smaller intact chromosomal molecules.

In the present work we utilize two alternatives that are more suitable for the dsb analysis in yeast. The first method utilizes the entire distribution of DNA from irradiated cells in a gel lane. The distribution is measured by laser densitometric scanning of a photonegative which is taken from a ethidium bromide-stained gel. A possible pitfall of this method is the response of the photographic film to the fluorescence emitted by the intercalated ethidium bromide. Due to reciprocity failure the blackening of the negative is saturated at long exposure. Calibration experiments have shown that a roughly linear response of the film is obtained with the parameters used in this study (data not shown). Furthermore the data obtained by the analysis of DNA distribution as measured by densitometry of the photonegative were confirmed by the hybridization assay. Nevertheless it would be desirable to measure the ethidium bromide signals directly by a charge-coupled device (CCD) camera or a comparable device.

DNA distributions were computed according to a multi-step process: a group of 16 chromosomal molecules was assumed, with sizes corresponding to the BK0 genome. The distribution of molecular lengths was then computed that results from random breakage of these molecules in a Poisson model of breaks distributed uniformly and independently on the chromosomes. The exact formula derived by Schulz (1942) for this process was used. The actual relation between molecular length and migration distance in individual gels is recognized from the position of the peaks in the gels. This relation is then used to transform the computed distribution of molecular length into the distribution of DNA in migration distances.

The computed DNA distribution curve is normalized to the same area under a preselected interval of the migration distances as the observed densitograms, and the best fit between computed and actual densitograms is then determined in terms of a leastsquares procedure. This provides the estimate of the frequency of dsb.

As can be seen from Figure 2 the computed and actual DNA distributions differ slightly for some bands in the gel. In our opinion this effect is caused by certain particularities of the karyotype of the strain BK0. This diploid strain was obtained by crossing of two haploid strains whose homologous chromosomes do not have identical lengths. Furthermore the strain BK0 shows a large number of double bands (see Figure 1). We used this strain because it serves as a repair-competent reference strain in our laboratory. By using a haploid strain with well separated chromosomes an even better accordance of actual and computed distributions should be attainable.

The frequencies of dsb obtained with the TAFE and CHEF configuration were pooled, as they showed no significant difference from each other. 
The appearance of the DNA distribution profiles is, of course, different for CHEF and TAFE gels, depending on the actual relation between molecular length and migration velocity. This relation is individually determined for each gel during the evaluation process, as the positions of the peaks are used to calculate a calibration curve. Hence, every PFGE configuration should be suitable as long as it produces straight lanes with the same lane width over the whole migration distance.

The number of dsb per unit molecular length appears to be linearly dependent on the dose from 250 to $1000 \mathrm{~Gy}$. This result is consistent with results from sedimentation studies in yeast and in mammalian cells (Frankenberg-Schwager et al. 1979, Blöcher 1982). In contrast to the observed linearity in these studies, several authors who used elution procedures have inferred a linear-quadratic dependence of dsb in mammalian cells on dose (e.g. Blazek et al. 1989, Radford and Hodgson 1985). Recent results, however, indicate that the determination of dsb by neutral elution is sensitive to minor changes in the details of the experimental procedure, and under certain conditions a linear dose-dependence is obtained (Okayasu and Iliakis 1989). By analysis of the pattern of DNA mass distribution a dsb frequency of $(1.07 \pm 0.06) \times 10^{-9} \mathrm{~Gy}^{-1} \mathrm{bp}^{-1}$ after $\gamma$ irradiation under anoxic conditions was obtained in our study.

In a second approach a subset of six gels was blotted and hybridized with chromosome-specific DNA probes. A chemiluminescence reaction was utilized to measure the resulting distributions. Calibration experiments showed the hybridization signal to be proportional to the number of target chromosomal molecules. Chromosome-specific determination of the fraction of intact chromosomal molecules after irradiation of the cells was then used to calculate the frequency of $\mathrm{dsb}$, and this was found to be $(0.93 \pm 0.09) \times 10^{-9} \mathrm{~Gy}^{-1} \mathrm{bp}^{-1}$, with the number of dsb per unit length being linearly dependent on dose (data not shown). The differences between the values obtained for different chromosome species were within the range of variations obtained in different experiments. Thus, it appears that the frequency of dsb per unit length induced by $\gamma$-irradiation under anoxic conditions is the same for all chromosomes.

The analysis of the patterns of DNA mass distribution and the analysis in terms of Southern hybridization led to dsb frequencies per unit dose that are in very good agreement. However, the values are about $20-30 \%$ lower than published data, which were obtained by sedimentation techniques for mammalian and yeast cells irradiated under anoxic con- ditions (Lennartz et al. 1975, Frankenberg-Schwager et al. 1979, Andrews et al. 1984). At present it is still uncertain whether the disagreement is caused by differences in the experimental procedures, or whether different kinds of DNA damage are monitored by the different techniques.

In conclusion we see a wide applicability of the assays which have been described in this paper. They can be employed for the analysis of the induction and repair of dsb after sparsely ionizing irradiations in all kinds of organisms with chromosomal molecules that can be separated by PFGE. The hydridization assay is somewhat more labour intensive, but it is especially suitable for chromosome-specific analysis. Further investigations will be required to determine whether these assays can also be employed for the analysis of $\mathrm{dsb}$ induced by densely ionizing radiation.

\section{Acknowledgements}

A.A.F. is promoted by the 'Studienstiftung des deutschen Volkes'.

\section{References}

Ager, D. D. and Dewey, W. C., 1990, Calibration of pulsed field gel electrophoresis for measurement of DNA double-strand breaks. International Journal of Radiation Biology, 58, 249-259.

Ager, D. D., Dewey, W. C., Gardiner, K., Harvey, W., Johnson, R. T. and Waldren, C. A., 1990, Measurement of radiation-induced DNA double-strand breaks by pulsed-field gel electrophoresis. Radiation Research, 122, $181-187$.

Ahn, S. Y., Nevaldine, B. and Hahn, P. J., 1991, Direct measurement by pulsed-field gel electrophoresis of induction and rejoining of X-ray-induced double-strand breaks in cultured mouse cells. International Journal of Radiation Biology, 59, 661-675.

Andrews, J., Martin-Bertram, H. and Hagen, U., 1984, S1 nuclease-sensitive sites in yeast DNA: an assay for radiation-induced base damage. International Journal of Radiation Biology, 45, 497-504.

Blazek, E. R., Peak, J. G. and Peak, M. J., 1989, Evidence from nondenaturing filter elution that induction of double strand breaks in the DNA of Chinese hamster V79 cells by $\gamma$-radiation is proportional to the square of dose. Radiation Research, 119, 466-477.

Blöcher, D., 1982, DNA double strand breaks in Ehrlich ascites tumour cells at low doses of X-rays. I. Determination of induced breaks by centrifugation at reduced speed. International Journal of Radiation Biology, 42, 314-328.

BLöcher, D., 1990, In CHEF electrophoresis a linear induction of DSB coresponds to a nonlinear fraction of extracted DNA with dose. International Journal of Radiation Biology, 57, 7-12. 
Blöcher, D. and Kuhni, M., 1990, DNA double-strand break analysis by CHEF electrophoresis. International Journal of Radiation Biology, 58, 23-34.

Blöcher, D. and Pohlit, W., 1982, DNA double strand breaks in Ehrlich ascites tumour cells at low doses of X-rays. II. Can cell death be attributed to double strand breaks? International Journal of Radiation Biology, 42, 329-338.

Blöcher, D., Einspenner, M. and Zajackowski, J., 1989, CHEF electrophoresis, a sensitive technique for the determination of DNA double-strand breaks. International Journal of Radiation Biology, 56, 437-448.

Bronstein, I., Voyta, J. C., Lazzari, K. G., Murphy, O., Edwards, B. and Kricka, L. J., 1990, Rapid and sensitive detection of DNA in Southern blots with chemiluminescence. Biotechniques, 8, 310-316.

Contopoulou, C. R., Cook, V. E. and Mortimer, R. K., 1987, Analysis of DNA double strand breakage and repair using orthogonal field alternation gel electrophoresis. Yeast, 3, 71-76.

Frankenberg, D., Frankenberg-Schwager, M., Blöcher, D. and HARBICH, R., 1981, Evidence for DNA doublestrand breaks as the critical lesions in yeast cells irradiated with sparsely or densely ionizing radiation under oxic or anoxic conditions. Radiation Research, 88, 524-532.

Frankenberg-Schwager, M., Frankenberg, D., Blöcher, D. and ADAmCZYK, C., 1979, The influence of oxygen on the survival and yield of DNA double-strand breaks in irradiated yeast cells. International Journal of Radiation Biology, 36, 261-270.

Geigl, E.-M. and Eckardt-Schupp, F., 1990, Chromosomespecific identification and quantification of S1 nucleasesensitive sites in yeast chromatin by pulsed field gel electrophoresis. Molecular Microbiology, 4, 801-810.

Geigl, E.-M. and EckardT-Schupp, F., 199la, The repair of DNA double-strand breaks and $\mathrm{Sl}$ nuclease sensitive sites can be monitored chromosome-specifically in Saccharomyces cerevisiae using pulsed field gel electrophoresis. Molecular Microbiology, 5, 1615-1620.

Geigl, E.-M. and Eckardt-Schupp, F., 1991b, Repair of gamma ray-induced $\mathrm{S} 1$ nuclease hypersensitive sites in yeast depends on homologous mitotic recombination and a RAD18-dependent function. Current Genetics, 20, 33-37.

Geigl, E.-M., Eckardt-Schupp, F. and Hagen, U., 1986, Analysis of ${ }^{60} \mathrm{Co}$-gamma-induced bulky lesions in yeast chromatin by orthogonal field alteration gel electrophoresis. Yeast, 2, 126.

Hanawalt, P. C., 1986, Intragenomic heterogenicity in DNA damage processing: potential implications for risk assessment. In: Mechanisms of DNA Damage and Repair, edited by M. Simic, L. Grossman, A. Upton (Plenum Press, New York), pp. 489-498.

Ho, K. S. Y., 1975, Induction of DNA double strand breaks by $\mathrm{X}$-ray in a radiosensitive strain of the yeast Saccharomyces cerevisiae. Mutation Research, 30, 327-334.

Iliakis, G. E., Metzger, L., Denko, N. and Stamato, T. D., 199la, Detection of DNA double-strand breaks in synchronous cultures of $\mathrm{CHO}$ cells by means of asymmetric field inversion gel electrophoresis. International Journal of Radiation Biology, 59, 321-341.
Illakis, G. E., Gicilioni, O. and Metzger, L., 1991b, Measurement of DNA double-strand breaks in CHO cells at various stages of the cell cycle using pulsed field gel electrophoresis: calibration by means of ${ }^{125} \mathrm{I}$ decay. International Journal of Radiation Biology, 59, 343-357.

Jacobs, A., Bopp, A. and HAGEN, U., 1972, In vitro repair of single-strand breaks in gamma-irradiated DNA by polynucleotide kinase. International Journal of Radiation Bio$\log y, 22,431-436$.

Kessler, B., Bopp, A. and HAGeN, U., 1971, Radiationinduced single-strand breaks in double-stranded circular DNA. International Journal of Radiation Biology, 20, 75-78.

Kunz, B. A. and HAynes, R. H., 1982, DNA repair and the genetic effects of thymidylate stress in yeast. Mutation Research, 93, 353-375.

Lennartz, M., Coquerelle, T., Bopp, A. and Hagen, U., 1975, Oxygen-effect on strand breaks and specific endgroups in DNA of irradiated thymocytes. International Journal of Radiation Biology, 27, 577-587.

Madhani, H. D., Bohr, V. A. and Hanawalt, P. C., 1986, Differential DNA repair in transcriptionally active and inactive proto-oncogenes: $\mathrm{c}-\mathrm{abl}$ and c-mos. Cell, 45, 417-423.

Okayasu, R. B. and Iliakis, G., 1989, Linear DNA elution dose response curves obtained in CHO cells with nondenaturing filter elution after appropriate selection of lysis conditions. International Journal of Radiation Biology, 55, 569-581.

Oleinick, N. L., Chiu, S. and Friedman, L. R., 1983, Chromatin structure as a factor in the formation and rejoining of radiation-induced single strand breaks in mammalian cells. Proceedings of the 7th International Congress of Radiation Research (Martinus Nijhoff, Amsterdam), B2-28.

RADFord, I. R. and Hodgson, G. S., 1985, ${ }^{125}$ I-induced DNA double strand breaks: use in calibration of the neutral filter elution technique and comparison with X-ray induced breaks. International Journal of Radiation Biology, 48, 555-566.

Resnick, M. A. and Martin, P., 1976, The repair of doublestrand breaks in the nuclear DNA of Saccharomyces cerevisiae and its genetic control. Molecular and General Genetics, 143, 119-129.

Schulz, G. V., 1942, Über die Molekulargewichtsverteilungen, die beim Abbau von Stoffen mit Kettenmolekülen auftreten. Zeitschrift für Physikalische Chemie, 51, 127-141.

Smith, L. C., Klco, S. R. and Cantor, C. R., 1988, Pulsedfield gel electrophoresis and the technology of large DNA molecules. In: Genome Analysis-a Practical Approach, edited by K. E. Davis (IRL Press, Oxford and Washington, DC), pp. 41-61.

Stamato, T. D. and Denko, N., 1990, Asymmetric field inversion gel electrophoresis: a new method for detecting DNA double-strand breaks in mammalian cells. Radiation Research, 121, 196-205.

Terleth, C., Van Sluis, C. A. and Van de Putte, P., 1989, Differential repair of UV damage in Saccharomyces cerevisiae. Nucleic Acids Research, 17, 4433-4439.

WARD, J. F., 1990, The yield of DNA double-strand breaks produced intracellularly by ionizing radiation: a review. International Journal of Radiation Biology, 57, 1141-1150. 